\title{
LOW CYCLE FATIGUE BEHAVIOUR OF ALLOY 718 DISC FORGING AT ELEVATED TEMPERATURES
}

\author{
R.L.SAHA , K. GOPINATH ${ }^{*}$, K.K. SHARMA AND M. SRINIVAS ${ }^{* *}$ \\ Project Office (Materials) ${ }^{*}$, Defence Metallurgical Research Laboratory ${ }^{* *}$ \\ Kanchanbagh, Hyderabad 500058, INDIA
}

\begin{abstract}
Alloy 718 exhibits a crossover in fatigue lives at low strain and stress ranges when temperature increases from $298 \mathrm{~K}$ to $798 \mathrm{~K}$ and $898 \mathrm{~K}$. As expected, at high stress and strain ranges, lowest fatigue lives were exhibited at higher temperatures. However, in low stress and strain ranges the fatigue lives at $798 \mathrm{~K}$ and $898 \mathrm{~K}$ were found to be higher than at room temperature. The enhancement in cyclic life at elevated temperatures and low strain and stress ranges could be due to oxidation effect and plasticity induced crack closure. The break in plastic strain range versus $N$ plot at elevated temperatures corroborates the presence of an environmental effect.
\end{abstract}




\section{INTRODUCTION}

Acro engine turbine discs are highly critical components subjected to high mechanical stresses at elevated temperatures. During engine startup, shutdown and major throttle excursions in the course of a flight, the discs are subjected to cyclic stresses. Therefore, adequate fatigue strength is essential for turbine disc materials in addition to high tensile and creep strength. With disc stresses exceeding yield point of the material, low cycle fatigue strength becomes very important. Therefore, characterisation of the fatigue properties of disc alloys under conditions similar to that experienced by the actual operating dises assumes significance. One such established procedure is to evaluate fatigue properties of specimens cut-up from actual disc segments. Results obtained from such an exercise on Alloy 718 discs over a period of time revealed certain trend in the low cycle fatigue lives obtained from tests conducted in load and extension controlled modes. At room temperature, as expected, for a given stress/strain and frequency, the life to failure, $\mathrm{N}_{\mathrm{f}}$, was seen to reduce with increase in temperature. However. contrary to the expectations, lives of specimens tested at low strains were found to be higher at elevated temperature than at room temperature. The details of the observations and possible reasons for this behaviour are discussed here.

\section{ALLOY}

Alloy 718. with a nominal composition of Ni-19Cr-18Fe-5.1(Nb+Ta)-3.1Mo-0.9Ti-0.5Al $\left(w^{\circ} \%\right)$ possess excellent high temperature mechanical properties (strength, fatigue and creep) up to $650^{\circ} \mathrm{C}$ combined with good formability and weldability and is an ideal choice for various acro engine components. This precipitation strengthened superalloy has an FCC structure ( $\because$ matrix) which is solid solution strengthened by Iron, Chromium, and Molybdenum. The disc shaped. BCT structured and ordered intermetallic phase, $\gamma^{\prime \prime}$, is the principal strengthening phase in this alloy [1]. Coherency strains are introduced during the precipitation of $\gamma^{\prime \prime}$ (about 20-40) $\mathrm{nm})$ in the range of $700-900 \mathrm{C}$. Spherical and ordered intermetallic phase, $\mathrm{Ni}$ ( Ti, Al). designated as $\%$, that is precipitated in the temperature range of $600-700 \mathrm{C}$ interacts with the dislocations and contributes to secondary strengthening. The alloy contains about $13 \mathrm{vol} \%$ of $y^{\prime \prime}$ and $4 \mathrm{vol} \%$ of $\mathrm{r}^{\prime}$. Depending on the processing condition, delta ( $\delta$ ), $\mathrm{Ni}$, $\mathrm{Nb}$ phase can also be present. In addition. the presence of small amounts of $\mathrm{NbC}, \mathrm{TiC}$ and $\mathrm{TiN}$ also contribute to strengthening. Heat treatment of Alloy 718 consists of a solution treatment at high temperature followed by duplex ageing at intermediate temperature. Solution temperatures are chosen just below the $\delta$ solvus temperature so as to ensure dissolution of $\gamma^{\prime \prime}$ and $\gamma^{\prime}$ phases, but maintaining the fine grain size achieved by thermomechanical processing through the grain boundary pinning effect provided by $\delta$. Standard heat treatment of the alloy involves solutionising treatment of $980^{\circ} \mathrm{C} / 1 \mathrm{Hr} /$ water quench followed by ageing at $718^{\circ} \mathrm{C} / 8 \mathrm{Hrs}+$ furnace cooled to $621 \mathrm{C} / 8 \mathrm{Hrs}$ and aircooled.

\section{EXPERIMENTAL PROCEDURES}

Alloy 718 was melted and refined through the Vacuum Induction Melting (VIM) followed by Vacuum Arc Refining (VAR). The chemical composition of the alloy is presented in Table- 1 . $2.50 \mathrm{~mm}$ diameter billets having a fine grained structure (ASTM 8-10) were converted to an aero engine low pressure turbine disc of $475 \mathrm{~mm}$ outer dia and $215 \mathrm{~mm}$ inner dia through closed-dic forging (upsetting and finishing) using a $35 \mathrm{~K}$ hammer at $995^{\circ} \mathrm{C}$. The forgings were subjected to the standard solutionising and duplex ageing treatment referred above. 
Table 1: Chemistry of Alloy 718 forging feedstock

\begin{tabular}{c|c|c|c|c|c|c|c|c|c}
\hline $\mathrm{Ni}$ & $\mathbf{C r}$ & $\mathbf{N b}$ & $\mathbf{M o}$ & $\mathbf{T i}$ & $\mathbf{A l}$ & $\mathbf{C}$ & $\mathbf{O}$ & $\mathbf{N}$ & $\mathbf{F e}$ \\
\hline $53.95 \%$ & $17.72 \%$ & $5.35 \%$ & $2.94 \%$ & $0.95 \%$ & $0.52 \%$ & $0.025 \%$ & $13 \mathrm{ppm}$ & $58 \mathrm{ppm}$ & $\mathrm{Bal}$ \\
\hline
\end{tabular}

Prior to carrying out LCF tests, tensile tests were carried out to assess the tensile properties of the alloy. All blanks for machining tensile and low cycle fatigue (LCF) specimens were extracted from the heat treated forging in radial direction. The geometry of the specimens used for LCF testing is given at Fig. 1. The tensile tests were carried out in an Instron tensile testing machine at a strain rate of $0.002 \mathrm{sec}^{-1}$. The LCF tests were carried out using a closed loop servo controlled hydraulic machine of Dartech. USA. Load and extension controlled LCF tests were conducted in air under full tensile loading condition at $298 \mathrm{~K}, 798 \mathrm{~K}$ and $898 \mathrm{~K}$. All tests were conducted using a triangular wave form at a frequency of $0.3 \mathrm{~Hz}$ at $R=0.05$. This ' $R$ ' ratio is considered to closely represent the all-tensile fatigue condition experienced by an actual disc.

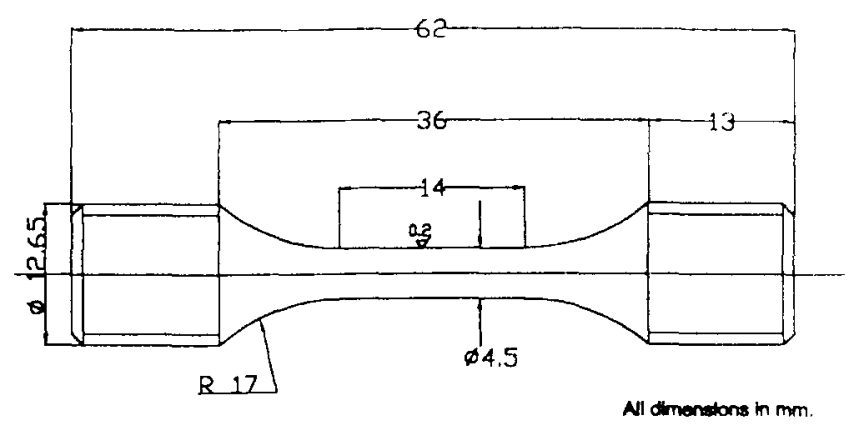

Fig 1: Geometry of the specimen used for LCF testing

\section{RESULTS AND DISCUSSION}

A typical microstructure of the disc forging from which test specimens were extracted is shown in Fig 2. Samples were etched using Kalling's reagent. The microstrcture revealed a $\gamma$ matrix with a relatively uniform grains of size ASTM 9-10 (ie., 10-15 ) with occasional banding at some places.

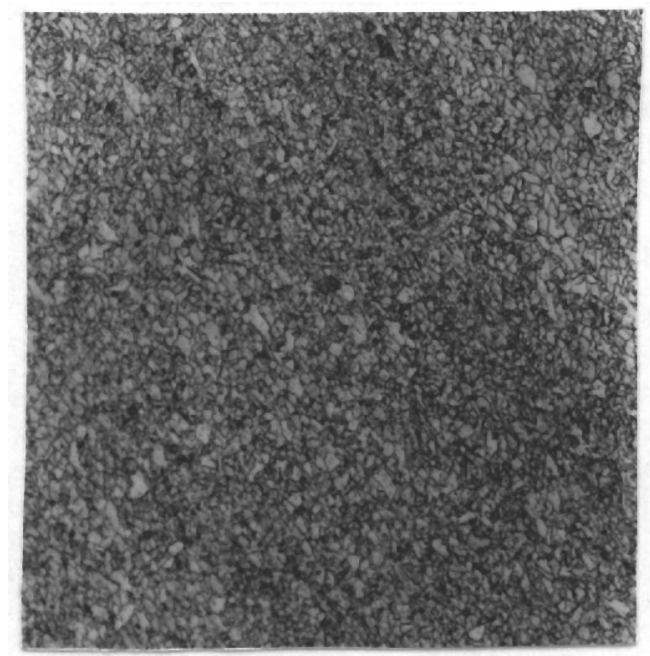

Fig 2: Optical Micrograph of Alloy 718 at $100 \mathrm{X}$. 
The yeld strength and lis obtaned from the tensile tests are given in Fig 3 . The $0.2 \%$ yicht strength and ultimate strength were found to marginally decrease with increase in temperature. The drop in yield and ultimate tensile strengths from room temperature to $898 \mathrm{~K}$ is approximately $15 \%$ indicating excellent high temperature strength of this alloy. The high strength levels exhibited by this alloy at temperatures up to $898 \mathrm{~K}$ are primarily attributable to the "precipitates. which provide strengthening as a result of coherency strains between them and the $y$ matrix. The limitation in available slip direction for BCT structured $\gamma$ " also contributes (1) its high elevated temperature strength [1]. In addition, other traditional strengthening mechanisms such as solid solution strengthening and dislocation interaction with $\gamma^{\prime}$ particles Atso contribute to strength.

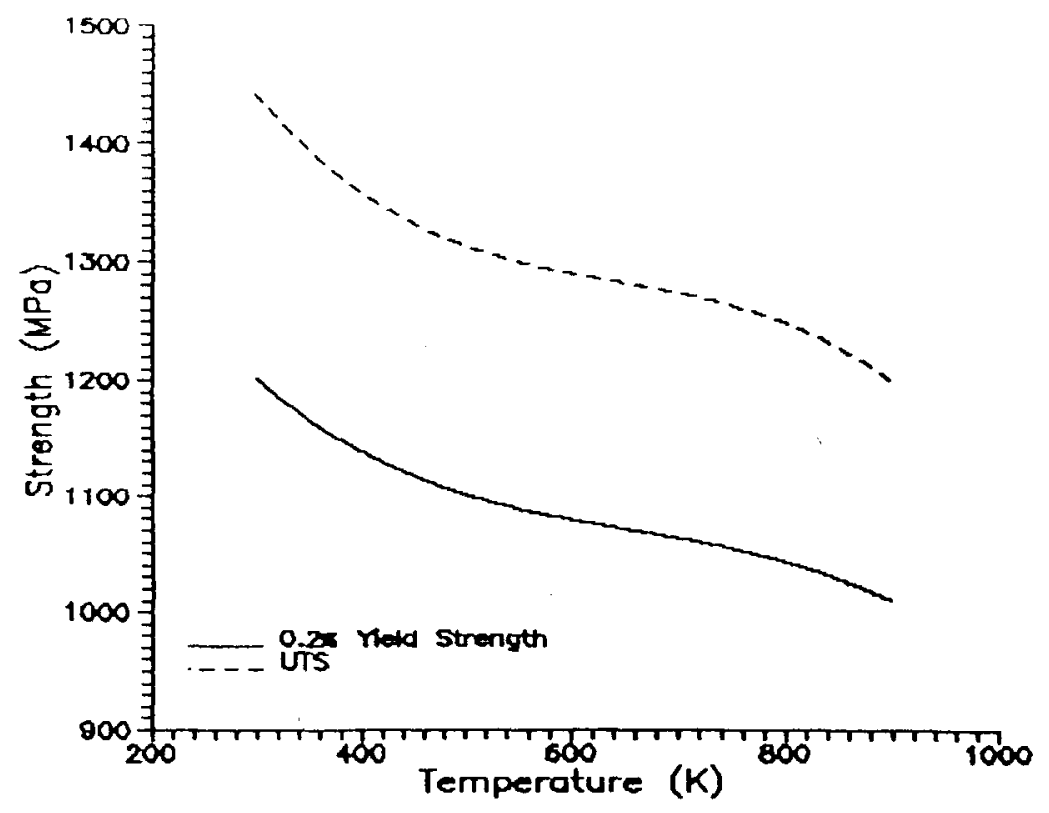

Fig 3: Variation of $0.2 \%$ YS and UTS with temperature.

\section{LCF Properties:}

Stress Cycling: The effect of stress cycling on the fatigue life of Alloy 718 is shown in Fig 4 From the slope of the lines, it is evident that the LCF lives are highly sensitive to stress range at the elevated temperatures of $798 \mathrm{~K}$ and $898 \mathrm{~K}$ rather than at $298 \mathrm{~K}$. Retention of reasonably useful LCF lives of about $10^{3}$ cycles could be observed at stress levels as high as $95 \%$ of its LTS at temperatures studied. At high stress ranges, fatigue lives were found to reduce with increase in temperature as expected, but a crossover in fatigue lives were observed at lower stresses i.e. at lower stresses. fatigue lives at $798 \mathrm{~K}$ to $898 \mathrm{~K}$ were higher than at $298 \mathrm{~K}$. This is contrary to the expected decrease in strength with increase in temperature. The crossover is observed below the stress range of about $1030 \mathrm{MPa}$. However, increasing the test temperature from $798 \mathrm{~K}$ to $898 \mathrm{~K}$ decreased the life at all stress ranges.

The observed fatigue behaviour is in line with that reported by Kawagoishi et al [2] on Inconel 718 and can be explained as follow's. Kawagoishi et al [2] in their study found that the initiation and growth of cracks is governed by two phenomena. i.e., 1) a suppression action due to oxide film formed on the surface of the specimens and 2) a promotion action due to softening of the $\gamma$ matrix. Considering that LCF is primarily a crack propagation process, they have concluded that suppression of crack growth at elevated temperatures due to oxide formation and plasticity induced crack closure resulted in a longer LCF life at low stress amplitudes. 


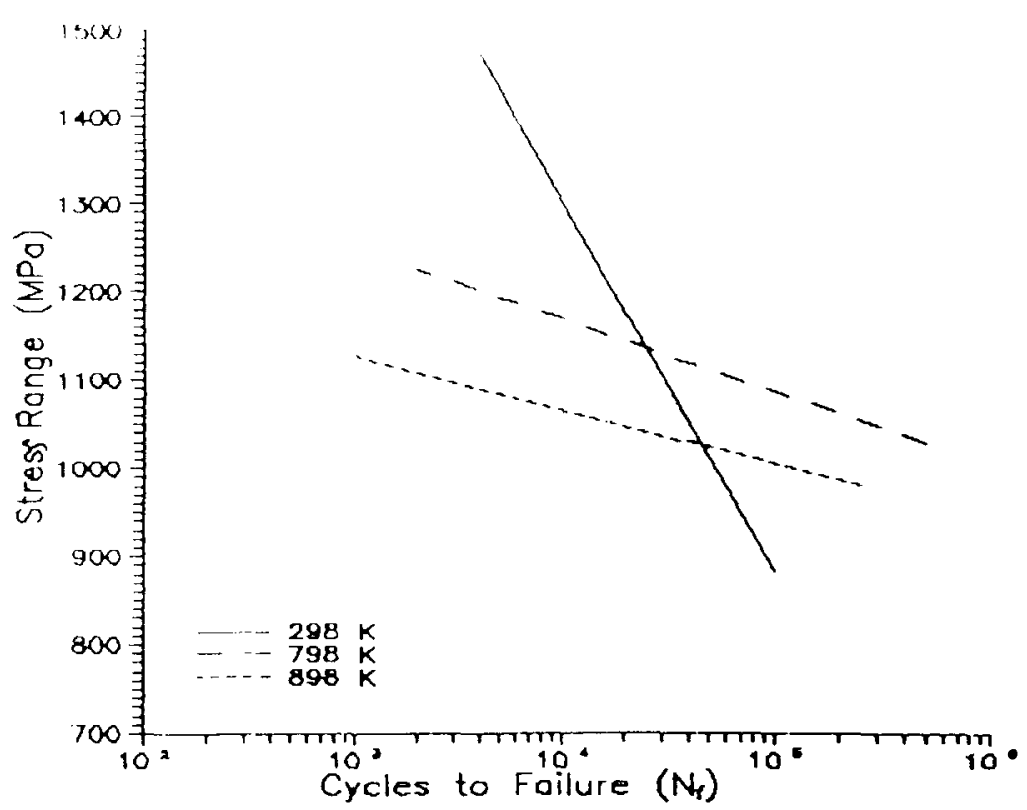

Fig 4: Total stress range vs number of cycles to failure, $\mathrm{N}_{\mathrm{f}}$ at $298 \mathrm{~K}, 798 \mathrm{~K}$ and $898 \mathrm{~K}$

Strain Cycling: Fig 5 shows the effect of strain cycling on the fatigue life of Alloy 718 at 298 $\mathrm{K}, 798 \mathrm{~K}$ and $898 \mathrm{~K}$. It is evident from Fig 5 that the dependence of number of cycles to failure on total strain range at room temperature is unchanged while at elevated temperatures of $798 \mathrm{~K}$ and $898 \mathrm{~K}$ the material response changes. When strain range is less than about $1 \%$ and $N_{1}$ exceeds about $5 \times 10^{3}$ cycles, life time at a given total strain range is greater at two elevated temperatures than that at the room temperature. Fig 6 is a plot of plastic strain range $v s$ number of cycles to failure. It is evident from Fig 6 that above plastic strain range value of $0.3 \%$, the life is less at elevated temperatures, while below $0.3 \%$ the life to failure is more at elevated temperatures as compared to room temperature. It is also to be noted from Fig 6 that at elevated temperatures of $798 \mathrm{~K}$ and $898 \mathrm{~K}$ the Coffin-Manson relationship does not describe the relationship between plastic strain and life throughout the range examined. The two-siope behaviour observed in this study at the two elevated temperatures is similar to that observed by Sunders et al [3] in Alloy 718 . The two slope behaviour in the strain range $v s \mathrm{~N}_{f}$ could be explained using the analysis of Coffin [4]. Coffin [4] attributes the presence of a break in the curve to an environmental effect. which would also reflect on fracture mode. At low strain ranges. the life of the specimen is much greater than at high strain ranges. Thus the time at clevated cemperature is longer at low strain ranges wherein the environmental effect is expected wi) be more pronounced. At elevated temperatures, large plastic strains are known to produce unnemulur fracture and low plastic strain produce intergranular fracture. Thus, at high comperatures, a break in the curve is anticipated. The transition from transgranular to mergramular fracture and the rate of intergranular cracking could be related to creep componem and the amount of oxidation occurring in a fatigue cycle [5]. Consequently, the total failure mechanism changes with total exposure time and strain range. Hence, at high strain ranges the failure is predominantly mechanical. whereas at low strain ranges, the process is accelerated by the contribution of either temperature and or environment. 


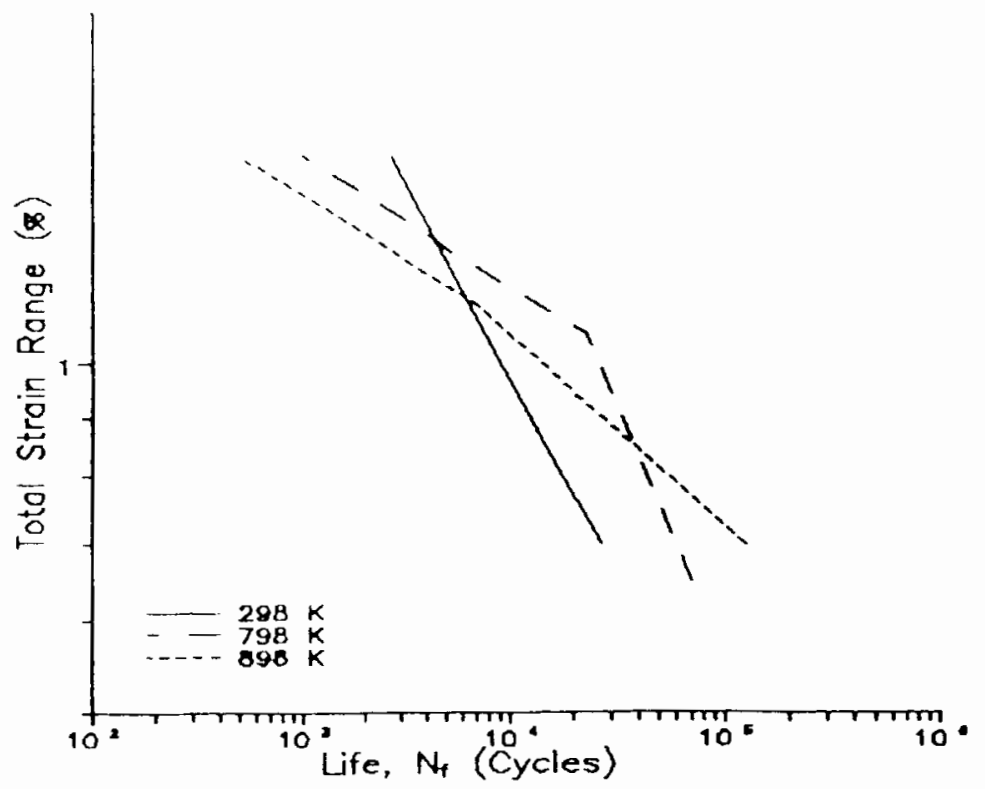

Fig 5: Total strain range vs number of cycles to failure, $\mathrm{N}_{\text {, }}$ at $298 \mathrm{~K}, 798 \mathrm{~K}$ and $898 \mathrm{~K}$.

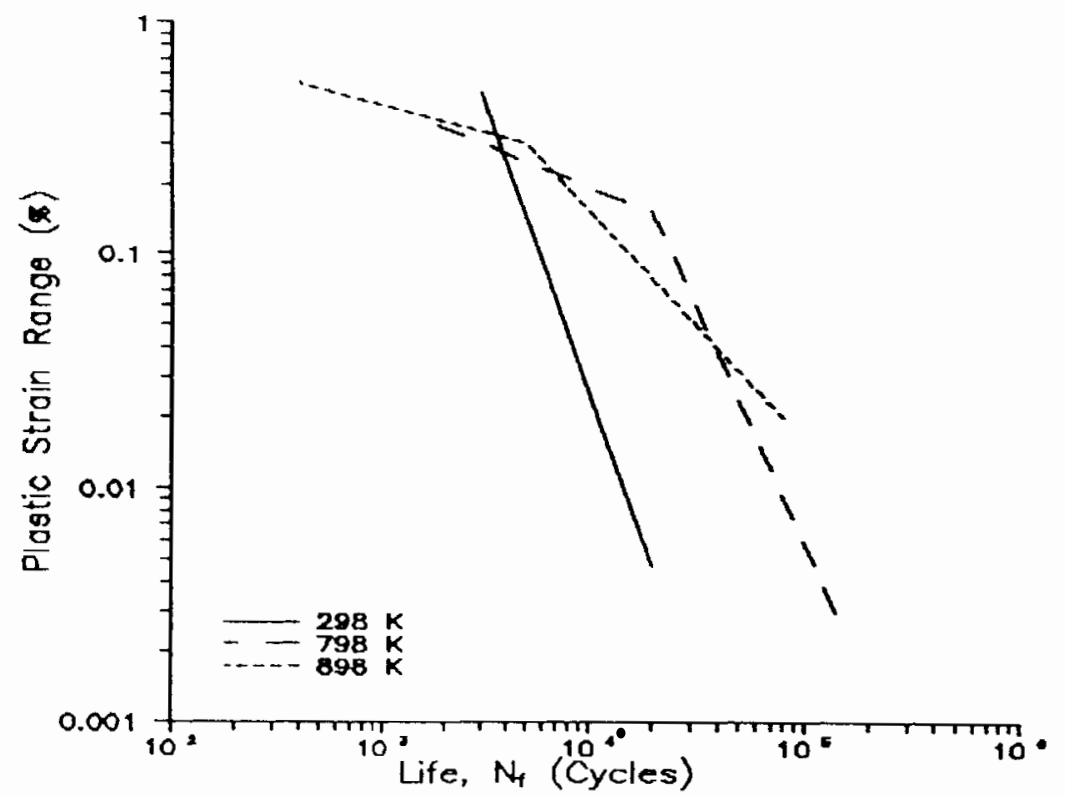

Fig 6: Plastic strain range is number of cycles to failure, $\mathrm{N}$, at $298 \mathrm{~K} .798 \mathrm{~K}$ and $898 \mathrm{~K}$

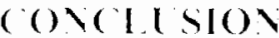

It can be concluded that the enhancement in cyclic life at elevated temperatures in stress controlled fatigue could be due to oxidation effect and plasticity induced crack closure, while the break in strain range vs $N$, plot at elevated temperatures could be due to oxidation effect again due to temperature and environment. 


\section{REFERENCES}

I. C.T. Sims. N.S. Stoloff and W.C. Hagel, ed. Superalloys II (New York. NY: John Wiley \& Sons. 1987). 165-188.

2. N.Kawaigoshi. Q.Chen and H.Nisitani, "Fatigue strength of Inconel 718 at elevated temperatures", Fatigue Fract Engng Mater Struct, 23 (2000), 209-216.

3. T.H. Sanders. Jr.. R.E.Frismuth and G.T.Embley, "Temperature Dependent Deformation Mechanisms of Alloy 718 in Low Cycle Fatigue". Met. Trans A, 12A (1981). 1003-1010.

4. L.F Coffin. Jr. "A Vote on Low Cycle Fatigue Laws", Journal of Materials, 6 (2) (1971). $388-402$.

5. M.Gell and G.R.Leverant, "Mechanism of High-Temperature Fatigue". Fatigue at Elevated Temperatures, ASTM STP 520. American Society for Testing and Materials. (1973), 37-67. 